ferred to a beaker, acidified with sulphuric acid, boiled down to less than ID cc., and finished as in phosphorus determinations, by reducing with zinc, and titrating with permanganate.

The blank or dummy test is a highly important one. It must be done on a molybdenum-free steel in exactly the same way as the test: the same amount of hydrochloric acid and the same amount of chromium. Both the hydrochloric acid and the chromium affect the dummy, the former very greatly, and the latter slightly.

Permanganate.

cc.

Dummy test, without hydrochloric acid............ 0.6

Dummy test, with hydrochloric acid............... I.2

Below are results obtained by use of the latter dummy result (chromium not added) in steels containing same amount of chromium as molybdenum.

\begin{tabular}{|c|c|c|}
\hline No. & $\begin{array}{l}\text { Molybdenum present. } \\
\text { Per cent. }\end{array}$ & $\begin{array}{l}\text { Moiybdenum found. } \\
\text { Per cent. }\end{array}$ \\
\hline $\begin{array}{l}1 \ldots \ldots \ldots \\
2 \ldots \ldots\end{array}$ & $\begin{array}{ll}\cdots \cdots & 1.05 \\
\cdots \cdots & 2.61\end{array}$ & $\begin{array}{l}1.12 \\
2.65\end{array}$ \\
\hline$\ldots \ldots \ldots$ & $\ldots \ldots$ & 5.35 \\
\hline
\end{tabular}

Although the most of the chromium is precipitated with the iron, it would seem from these results that enough passes into solution to slightly affect the end-point of titration. Hence the necessity for its presence in the dummy test.

In the gravimetric method the first lead molybdate precipitate is always contaminated with a little chromate.

LABORATORY OF HENRY DISSTON \& SONS' STEEL WORKS, PHILADELPHA.

\title{
PRELIMINARY NOTE ON A NEW SEPARATION OF THORIUM.
}

By FLOYD J. METZGER.

Received Januasy 6, rgos.

$\mathrm{N}$ an investigation still in progress, attention has been particularly directed to the use of the weaker organic acids for the separation of thorium from cerium, lanthanum, and didymium, and it is in this field that it is desired to announce some preliminary results.

It is found that from a 40 per cent. alcoholic solution, thorium is precipitated quantitatively on the addition of fumaric acid, while no change is produced by that reagent in cold solutions of cerium, lanthanum, or didymium. 
The experiments already made show that a good quantitative separation of thorium from these elements can be based upon this reaction. When thorium is precipitated in this manner in the presence of either cerium, lanthanum, or didymium, traces of the latter elements are carried down, but may be removed by a single reprecipitation. It is intended to compare this method with those at present in use for the analysis of monazite.

A number of other weak organic acids are being investigated along the same lines, and several of these show interesting results.

Quantitative Chemical I,aboratory, COLUMBIA LNIVERSITY.

\section{NOTE.}

Reinsch's Test for Arsenic.-To obtain a black deposit upon a piece of copper is a comparatively easy matter; to prove that this deposit is due to the presence of arsenic is perhaps more difficult. In place of the usual glass tube, Sheridan Delépine ${ }^{1}$ recommends a "thimble-shaped copper cone" half an inch high, inserted through a hole in a thin iron plate, the sublimate of arsenious oxide being formed on a microscope cover glass. The following simplified form of the above arrangement I have found extremely convenient for the detection of very minute quantities of arsenic.

In the center of a piece of sheet copper an inch or so square, a small depression is punched, an eighth of an inch deep and of about the same diameter. The arsenic is deposited from solution on a little piece of copper a few millimeters in area. After being washed and dried, the little piece of blackened copper is placed in the depression in the sheet metal. A microscope cover glass, having a drop of water on its upper surface, is now placed over the miniature copper crucible, and the latter is then gently heated over a very small flame. When examined under a high power of the microscope, the crystals of arsenious oxide may sometimes be seen even when no sublimate is visible to the naked eye. Careful attention to the illumination is, of course, necessary. 